\title{
Smoking and Parkinson's disease
}

\author{
RB GODWIN-AUSTEN, PN LEE, MG MARMOT, GM STERN
}

From the Department of Neurology, Derbyshire Royal Infirmary, Derby, Department of Medical Statistics and Epidemiology, London School of Hygiene and Tropical Medicine and the Department of Neurology, University College Hospital, London

SUMMARY In a case control study of the relationship between smoking habits and Parkinson's disease a negative association was demonstrated with a relative risk of $0 \cdot 52$. A history of smoking up to 20 years earlier was associated with a risk of developing Parkinson's disease equal to about half that in non-smokers. The type of disease, age of onset and rate of progression were associated with a similar reduction in risk implying that in respect of smoking history the disease is homogeneous. The positive correlation of degenerative vascular disease with smoking is further evidence that arteriosclerosis is not involved in the causation of Parkinson's disease. The negative association between Parkinson's disease and smoking is confirmed and is independent of other associated factors. The known and serious risks of smoking far outweigh the possible benefit of lowered risk of Parkinson's disease.

While smoking is well-known to be associated positively with a number of common diseases, there are some rarer diseases for which evidence of a negative association has been seen. The observation that Parkinson's disease is less common in smokers than non-smokers was first made by Kahn ${ }^{1}$ and has subsequently been confirmed by several other studies. ${ }^{2-6}$ The causation of Parkinson's disease is unknown but the relationship of this disease to smoking history may provide an important aetiological clue. The study reported here formed part of a larger study into possible aetiological factors in Parkinsonism. The aim was to achieve a case-control survey randomised throughout England, Scotland and Wales and avoiding self-selection by patients. Previous case-control studies have been reported but they have either relied on hospital patients ${ }^{2}$ or have been localised geographically. ${ }^{5}$

The objectives of this study were to confirm Baumann and his colleagues' findings ${ }^{5}$ of a reduced incidence of Parkinsonism related to smoking before the onset of the disease. This observation suggests that the association is not an artefact attributable to the subject giving up smoking because of the disease. We also wished to determine whether smoking

Address for reprint requests: Dr RB Godwin-Austen, Department of Neurology, Derbyshire Royal Infirmary, London Road, Derby DE1 2QY, UK.

Received 9 February 1982. Accepted 7 March 1982 alters the natural history of Parkinson's disease by delaying the onset of symptoms or whether smoking is associated with a milder or less progressive form of the disease, and to investigate whether the association of smoking with Parkinsonism might be an artefact due to a joint association with some other confounding factor less common in smokers. Finally, since there is an increased incidence of cardiovascular disease including stroke in smokers we wished to investigate the epidemiological relationships between vascular disease, Parkinsonism and smoking.

\section{Methods}

Permission was obtained from their General Practitioners to interview 383 patients with Parkinson's disease (cases) and a corresponding number of age/sex/practice individually matched controls. The practices were located throughout England, Scotland and Wales. Respondents, with the assistance of their spouses in some cases, answered questions concerning eight symptoms of Parkinson's disease (for example slowness in walking) to determine, for the majority of symptoms at least, the presence of the symptom during the last 6 months (and if so its severity at worst) or at some time in the past and the year at which it was first noticed. A detailed history was obtained on smoking habits and on a wide variety of factors of possible implication in the aetiology of Parkinsonism. Full details of the study method will be described elsewhere.

This paper is based on answers from 350 case-control pairs (179 men, 171 women) for whom adequate informa- 
tion on smoking habits and time of onset of the various symptoms of Parkinsonism was available. For some analyses, the association between a factor and the disease was assessed using matched-pair methodology. Thus from the ratio of the number of pairs for which the factor was present in the case and absent in the control to the number of pairs in which the converse was true, an estimate of the relative risk of the disease in relation to the factor could be obtained. In these analyses the significance of the relative risk was determined using McNemar's test ${ }^{7}$ and the significance of variation in relative risk between different defined sets of case/control pairs was assessed by a chisquared test. In other analyses, unmatched methodology was used, relative risk of Parkinson's disease being calculated from the overall distributions of the case and control populations rather than from the numbers of discordant pairs. In these analyses, relative risk estimates for the two sexes combined and their significance were calculated using the method of Dean et al. ${ }^{8}$

In one of the tables presented in the results section, scores are given for severity and progressiveness of Parkinson's disease. The severity score is a combined score derived by principal components analysis from the individual severity scores for each symptom of Parkinsonism. Progressiveness was defined by the ratio of the severity score to the number of years since the onset of the first symptom.

\section{Results}

At the time of interview there were 45 case-control pairs (27 male, 18 female) in which the case was a current smoker and the control was a non-smoker. This figure was significantly less $(p<0.001)$ than the 87 pairs (51 male, 36 female) in which the control smoked and the case did not, and confirmed the strong negative association between Parkinson's disease and smoking (relative risk 0.52 ). In order to test whether this association might have been an artefact due to the disease affecting smoking habits, we compared smoking habits at time of reported onset of the disease, and the 20 years earlier, in cases, with that of controls at the same time. Both at time of onset (relative risk $0.53 ; \mathrm{p}<0.001$ ) and 20 years earlier (relative risk $0.55 ; \mathrm{p}<0.01$ ), the conclusion that smoking was associated with about half the risk of Parkinson's disease was unaltered. Table 1 shows that, for both sexes, the greatest difference

Table 1 Distribution of smoking habits in cases and controls

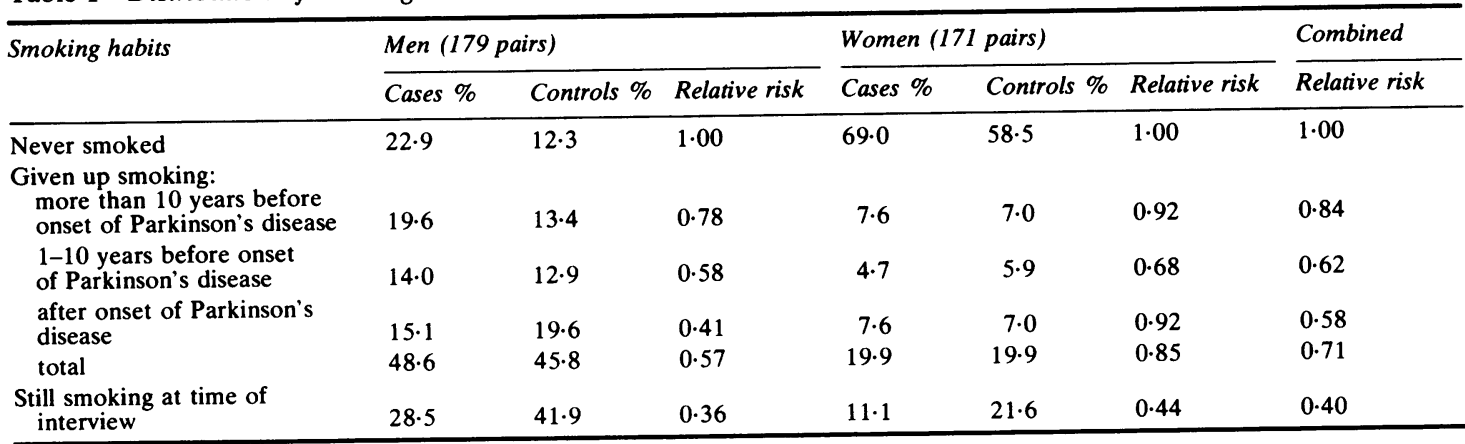

Table 2 Distribution of various aspects of the smoking habit in cases and controls

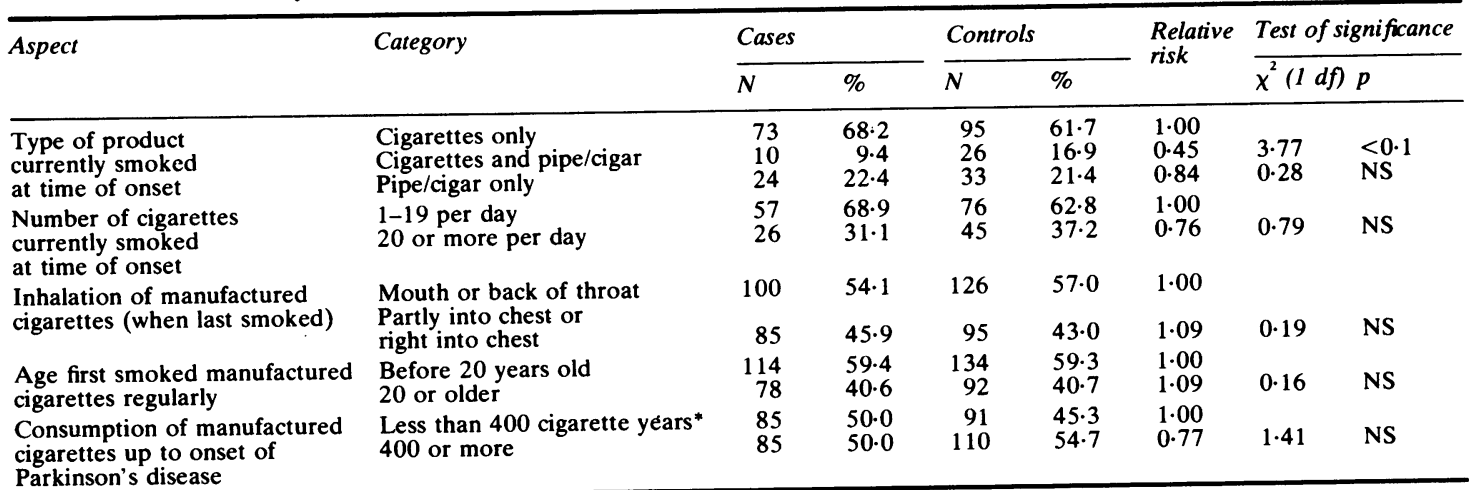

*One cigarette year is defined as one cigarette a day smoked for a year. 
in risk of Parkinson's disease was between those who were still smoking at the time of interview and those who had never smoked. Those who had given up smoking had an intermediate risk with a trend towards risk being lower in those who gave up later than earlier.

In Table 2 we investigated how various aspects of the smoking habit related to the risk of Parkinson's disease. No relationship was seen between the type of product smoked, degree of inhalation or age of starting to smoke and risk of the disease but there was some indication of a lower risk in those who smoked more heavily than in those who smoked less heavily though this was not statistically significant. We also studied the association between Parkinson's disease with type of cigarette smoked categorised by tar and nicotine content and carbon monoxide, but no consistent pattern was seen.
The question of whether smoking was associated with a particular form of Parkinson's disease was studied (table 3 ) by determining whether the magnitude of the reduction in risk of the disease in relation to smoking varied according to some characteristic of the disease. The results show that, whether cases were subdivided by groupings based on the overall severity score, the overall progressiveness score, age of onset or on degree of severity of shaking of the hands or speech difficulty (two symptoms of Parkinsonism found to be most independent of the overall severity score), in each subdivision smoking was associated with a similar reduction in risk. We will show elsewhere that, apart from the lower frequency of smokers in Parkinson's disease cases, the only significant case-control differences seen in our study were that cases were more likely to have had a head injury causing concussion

Table 3 Comparison of smoking habits* of cases and controls subdivided by various categorisations of the disease

\begin{tabular}{|c|c|c|c|c|c|c|c|}
\hline \multicolumn{2}{|l|}{ Type of case } & \multicolumn{2}{|c|}{ Number of pairs for which } & \multirow{2}{*}{$\begin{array}{l}\text { Relative } \\
\text { risk }\end{array}$} & \multicolumn{3}{|c|}{$\begin{array}{l}\text { Test of variation in } \\
\text { relative risk by level }\end{array}$} \\
\hline Category & Level & $\begin{array}{l}\text { Case smokes, } \\
\text { control does not }\end{array}$ & $\begin{array}{l}\text { Control smokes, } \\
\text { case does not }\end{array}$ & & $x^{2}$ & $d f$ & $p$ \\
\hline Severity & $\begin{array}{l}4+ \\
3-3 \cdot 9 \\
2-2 \cdot 9 \\
<2\end{array}$ & $\begin{array}{r}6 \\
17 \\
13 \\
18\end{array}$ & $\begin{array}{l}13 \\
31 \\
31 \\
26\end{array}$ & $\begin{array}{l}0.46 \\
0.55 \\
0.42 \\
0.69\end{array}$ & $1 \cdot 35$ & 3 & NS \\
\hline Progressiveness & $\begin{array}{l}1+ \\
0.5-0.9 \\
<0.5\end{array}$ & $\begin{array}{r}9 \\
15 \\
30\end{array}$ & $\begin{array}{l}17 \\
29 \\
52\end{array}$ & $\begin{array}{l}0.53 \\
0.52 \\
0.58\end{array}$ & 0.09 & 2 & NS \\
\hline Age of onset & $\begin{array}{l}\text { Less than } 50 \\
50-59 \\
60-69 \\
70 \text { or more }\end{array}$ & $\begin{array}{l}14 \\
11 \\
16 \\
13\end{array}$ & $\begin{array}{l}24 \\
21 \\
39 \\
17\end{array}$ & $\begin{array}{l}0.58 \\
0.52 \\
0.41 \\
0.76\end{array}$ & $1 \cdot 82$ & NS & \\
\hline Shaking of the hands & $\begin{array}{l}\text { Grade III } \\
\text { Grade II } \\
\text { Grade I } \\
\text { in the past }\end{array}$ & $\begin{array}{r}9 \\
13 \\
19 \\
3\end{array}$ & $\begin{array}{r}18 \\
33 \\
33 \\
4\end{array}$ & $\begin{array}{l}0.50 \\
0.39 \\
0.58 \\
0.75\end{array}$ & $1 \cdot 06$ & 3 & NS \\
\hline Speech difficulty & $\begin{array}{l}\text { Grade III } \\
\text { Grade II } \\
\text { Grade I } \\
\text { in the past }\end{array}$ & $\begin{array}{r}2 \\
19 \\
3 \\
4\end{array}$ & $\begin{array}{r}3 \\
40 \\
7 \\
7\end{array}$ & $\begin{array}{l}0.67 \\
0.48 \\
0.43 \\
0.57\end{array}$ & $0 \cdot 22$ & 3 & NS \\
\hline
\end{tabular}

*Smoking habits are measured at time of onset of first (or stated) symptom in cases and at same time in controls.

Table 4 Effect of various other factors on relative risk of Parkinson's disease in relation to smoking*

\begin{tabular}{|c|c|c|c|c|c|}
\hline \multirow[t]{2}{*}{ Factor } & \multicolumn{3}{|c|}{ Relative risk of Parkinson's disease in relation to smoking } & \multicolumn{2}{|c|}{$\begin{array}{l}\text { Test of variation in relative risk } \\
\text { according to presence of factor }\end{array}$} \\
\hline & $\begin{array}{l}\text { Standardised } \\
\text { for factor }\end{array}$ & $\begin{array}{l}\text { When factor } \\
\text { present }\end{array}$ & $\begin{array}{l}\text { When factor } \\
\text { not present }\end{array}$ & $\chi^{2}(1 d f)$ & $p$ \\
\hline $\begin{array}{l}\text { History of heart disease } \\
\text { History of hypertension } \\
\text { History of stroke } \\
\text { History of infarction } \\
\text { Had a head injury causing } \\
\text { concussion } \\
\text { Family history of Parkinson's } \\
\text { disease } \\
\text { Alcohol three or more times } \\
\text { a week }\end{array}$ & $\begin{array}{l}0.49 \\
0.51 \\
0.52 \\
0.53 \\
\\
0.52 \\
0.52 \\
\\
0.56\end{array}$ & $\begin{array}{l}0.93 \\
0.51 \\
0.92 \\
0.79 \\
0.58 \\
0.36 \\
0.70\end{array}$ & $\begin{array}{l}0.44 \\
0.52 \\
0.50 \\
0.52 \\
0.50 \\
0.52 \\
0.52\end{array}$ & $\begin{array}{l}2.62 \\
0.00 \\
0.79 \\
0.51 \\
0.12 \\
0.18 \\
0.61\end{array}$ & $\begin{array}{l}\text { NS } \\
\text { NS } \\
\text { NS } \\
\text { NS } \\
\text { NS } \\
\text { NS } \\
\text { NS }\end{array}$ \\
\hline
\end{tabular}

${ }^{*}$ Smoking is defined as current smoking at time of onset of Parkinson's disease. 
or a family history of Parkinson's disease. They were less likely to have, or to have had in the past, vascular disease or to be drinkers of alcohol. It is important to know whether any of these factors might affect the smoking/Parkinsonism relationship. In table 4 , therefore, we present the relative risk of Parkinson's disease in relation to smoking, standardised for each of these factors. It can be seen that the standardised relative risks varied little from the unstandardised risk demonstrating that the association of smoking with Parkinsonism is not an artefact due to both being related to any of these potential confounding factors. Although it is clear there is a smoking association for the whole data it is also of interest to investigate whether this association might vary according to presence or absence of any of these other factors. An analysis of our data did not show any statistically significant variation in the association with smoking according to presence or absence of any of these factors. However it should be realised that the estimates of relative risk when the factors are present are in most cases based on small numbers and have quite large variation.

The apparently independent relationships of alcohol and smoking to Parkinsonism are of interest. Further calculations showed the risk of Parkinson's disease in those who smoked and drank alcohol three or more times a week was $35 \%$ of that in those who did neither; however, the negative association between alcohol and Parkinson's disease is at least in part due to the cases having reduced their alcohol consumption to a greater extent than had the controls.

\section{Discussion}

These results provide confirmation of the negative correlation between smoking and Parkinson's disease. They are compatible with the observations originally reported by Kahn. ${ }^{1} \mathrm{Kahn}$ 's results gave a mortality ratio from Parkinson's disease in nonsmokers that was at least three times that in smokers. Doll and Peto's study' confirmed these observations in a study of mortality over 20 years in British doctors. In a case control study, Kessler and Diamond $^{3}$ found that the risk of Parkinson's disease in smokers was $66 \%$ of the risk for non-smokers. This ratio is similar to ours where a relative risk of $52 \%$ was demonstrated.

We were concerned to exclude artefacts due to the disease affecting smoking habits. It seemed probable that patients developing the symptoms of Parkinson's disease might alter their habits with respect to an activity such as smoking. Similarly levodopa may affect sense of taste and this might affect smoking habits. But we found different smok- ing rates up to 20 years before the onset of Parkinson's disease and the same relative risk applied. While we are aware of the difficulties of accepting the accuracy of reported smoking habits extending over two decades, this finding is supported by the longitudinal studies of mortality in relation to smoking. ${ }^{1}$ Baumann $e t$ al $^{5}$ suggested that the association of Parkinson's disease with smoking might be an artefact due to selective mortality, if patients who smoke succumb to illnesses associated with cigarette usage more than other smokers. This seems to us unlikely for two reasons. Firstly, the negative association was seen as clearly in younger and early onset patients, where selective mortality is of little significance, as it was in older and late onset patients. Secondly, there is some evidence ${ }^{10}$ that Parkinson's disease patients have a markedly reduced incidence of cancer, which, if confirmed, would tend to indicate the association of smoking with Parkinson's disease might be under- rather than over-stated. Parkinson's disease varies in its manifestations and rate of progression so that some patients present a predominantly tremulous form of the condition and seem to follow an unusually benign course, whereas others with hypokinetic disease may be much more rapidly disabled. The relationship with smoking is present for all forms of the disease. There is no excess of one type of Parkinson's disease in the smoking or non-smoking groups so that smoking history does not seem to alter the symptoms and signs of the disease nor to protect against any particular type of the condition.

Kessler and Diamond ${ }^{3}$ suggested a possible therapeutic role for nicotine to account for these observations. They proposed the hypothesis that nicotine provoked an increase in the elaboration of dopa by an alteration of the equilibrium between tryptophan and tyrosine metabolism. Such an effect, however, would be demonstrable only after the onset of the disease. Our observations-and we wish to emphasise that this is dependent on recollection over 20 years-appear to weigh against such a hypothesis because smoking 20 years before onset is important and also that the rate of progression of Parkinson's disease does not appear to be affected by smoking habits and that ex-smokers have a lower risk than non-smokers. It seems unlikely that a constituent of tobacco smoke has a therapeutic effect on Parkinson's disease.

Arteriosclerosis has been suggested as a possible cause of Parkinson's disease. Degenerative vascular disease and Parkinson's disease afflict similar age groups and some manifestations of cerebral arteriosclerosis may be clinically difficult to distinguish from Parkinson's disease. But there is a clear positive correlation between smoking and degenerative vascular 
disease in contrast to smoking and Parkinson's disease. Our results therefore suggest that arteriosclerosis is not involved in the causation of Parkinson's disease.

Several factors have been identified in the aetiology of Parkinsonism and these include viral infection, concussive head injury and genetic factors. Our data suggests that smoking may modify the effect of these factors. The causation of Parkinson's disease remains obscure but the negative correlation of this disease with cigarette smoking may have pathophysiological implications. The mortality and morbidity associated with smoking far outweighs any benefit from a possible lowering of risk of Parkinson's disease.

We thank the Parkinson's Disease Society and the Tobacco Advisory Council for their generous financial assistance with this study and Mrs Barbara George for her help with the preparation of the manuscript.

\section{References}

' Kahn HA. The Dorn study of smoking and mortality among US veterans. Report on eight and one-half years of observations. In: Epidemiological Approaches to the Study of Cancer and Other Chronic
Diseases. Monograph No.19. Washington, DC, National Cancer Institute, US Government Printing Office 1966, 1-125.

${ }^{2}$ Nefzger MD, Quadfasel FA, Karl VC. A retrospective study of smoking and Parkinson's disease. Am J Epidemiol 1967;88:149-58.

${ }^{3}$ Kessler II, Diamond KL. Epidemiologic studies of Parkinson's disease: I. Smoking and Parkinson's disease. Am J Epidemiol 1971;94:16-25.

${ }^{4}$ Kessler II. Epidemiologic studies of Parkinson's disease: III. A community based survey. Am J Epidemiol 1972;96:242-54.

s Baumann RJ, Jameson HD, McKean HE, Haack DG, Weisberg LM. Cigarette smoking and Parkinson's disease: 1 . A comparison of cases with matched neighbors. Neurology (Minneap) 1980;30:839-43.

' Marttila RJ, Rinne UK. Smoking and Parkinson's Disease. Acta Neurol Scand 1980;62:322-5.

${ }^{7}$ McNemar A. Note on the sampling error of the difference between correlated proportions or percentages. Psychometrika 1947;12:153.

${ }^{8}$ Dean G, Lee PN, Todd GF, Wicken AJ. Report on a second retrospective mortality study in North-East England. Part I. Tobacco Research Council, London 1977.

${ }^{9}$ Doll R, Peto R. Mortality in relation to smoking: 20 years observations on male British doctors. $\mathrm{Br}$ Med $\mathrm{J}$ 1976;2:1525-36.

${ }^{10}$ Marmot MG. Mortality and Parkinson's disease. In: Rose FC, Capildeo R, eds. Research Progress in Parkinson's disease. Tunbridge Wells: Pitman Medical. 1981. 